\title{
AUTOMATED TARGET PREPARATION FOR MICROARRAY-BASED GENE EXPRESSION
}

\section{ANALYSIS}

Frédéric Raymond ${ }^{1}$, Sylviane Metairon ${ }^{1}$, Roland Borner ${ }^{2}$, Markus Hofmann ${ }^{2}$, and Martin Kussmann ${ }^{1}$

${ }^{1}$ Nestle Research Center, Vers-chez-les-blanc, CH-1000 Lausanne 26, Switzerland.

${ }^{2}$ Hamilton Bonaduz AG, Life Science Robotics, Via Crusch 8, CH-7402 Bonaduz, Switzerland

\section{ABSTRACT}

The following supplementary information includes a correlation table, resulting from the comparison between a manual and an automated method of biotin-labelled cRNAs synthesis for gene expression analysis on Affymetrix GeneChip. 


\begin{tabular}{|lllllllll|}
\hline & M1 & M2 & M3 & M4 & M5 & M6 & M7 & M8 \\
\hline A1 & 0.987 & 0.988 & 0.986 & 0.988 & 0.986 & 0.981 & 0.986 & 0.988 \\
A2 & 0.988 & 0.989 & 0.987 & 0.988 & 0.986 & 0.981 & 0.988 & 0.989 \\
A3 & 0.991 & 0.992 & 0.990 & 0.992 & 0.989 & 0.980 & 0.986 & 0.989 \\
A4 & 0.989 & 0.991 & 0.988 & 0.990 & 0.987 & 0.979 & 0.986 & 0.987 \\
A5 & 0.989 & 0.991 & 0.989 & 0.990 & 0.987 & 0.977 & 0.985 & 0.986 \\
A6 & 0.991 & 0.990 & 0.989 & 0.991 & 0.988 & 0.979 & 0.986 & 0.988 \\
A7 & 0.987 & 0.989 & 0.987 & 0.989 & 0.986 & 0.980 & 0.988 & 0.989 \\
A8 & 0.986 & 0.988 & 0.986 & 0.987 & 0.985 & 0.980 & 0.988 & 0.987 \\
A9 & 0.992 & 0.991 & 0.990 & 0.991 & 0.990 & 0.983 & 0.990 & 0.990 \\
A10 & 0.993 & 0.992 & 0.991 & 0.992 & 0.991 & 0.981 & 0.988 & 0.989 \\
A11 & 0.992 & 0.992 & 0.993 & 0.993 & 0.991 & 0.983 & 0.991 & 0.990 \\
A12 & 0.993 & 0.995 & 0.993 & 0.995 & 0.993 & 0.986 & 0.993 & 0.995 \\
A13 & 0.992 & 0.993 & 0.992 & 0.994 & 0.991 & 0.984 & 0.991 & 0.993 \\
A14 & 0.992 & 0.989 & 0.990 & 0.991 & 0.990 & 0.983 & 0.991 & 0.990 \\
A15 & 0.991 & 0.992 & 0.992 & 0.993 & 0.992 & 0.988 & 0.993 & 0.993 \\
A16 & 0.992 & 0.993 & 0.991 & 0.992 & 0.990 & 0.978 & 0.987 & 0.987 \\
\hline
\end{tabular}

Table S-1. Pearson correlation coefficients comparing manual (M) and automated (A) methods. Eight samples have been prepared manually while 16 samples have been processed with the automated method in two runs of 8 samples each. 